\title{
Evaluating adherence to ocular hypotensives using the Travatan dosing aid
}

This article was published in the following Dove Press journal:

Clinical Optometry

18 January 2012

Number of times this article has been viewed

\section{Leslie O'Dell'}

Amy L Hennessy 2,3

Alan L Robin ${ }^{2-4}$

'May Eye Care Center, Hanover, PA, USA; ${ }^{2}$ Johns Hopkins Bloomberg School of Public Health, Baltimore, MD, USA; ${ }^{3}$ Glaucoma Specialists, Baltimore, MD, USA; ${ }^{4}$ Wilmer Eye Institute, Johns Hopkins School of Medicine, Baltimore, MD, USA
Correspondence: Leslie O’Dell

May Eye Care Center,

250 Fame Avenue Suite 225,

Hanover, PA 1733I-I587, USA

$\mathrm{Tel}+\mathrm{I} 717521$ 7|6I

Email leslieod@hotmail.com
Purpose: The Travatan ${ }^{\mathrm{TM}}$ Dosing Aid (TDA) is the first commercially available device designed to aid in patients' adherence to their glaucoma therapies and to record patients' eyedrop administration, so that doctors can better assess adherence. No prior studies have objectively evaluated adherence to glaucoma medications and its relationship to the severity of glaucoma or the use of multiple systemic medications.

Methods: We enrolled 100 consecutive subjects from a private glaucoma practice, all currently using topical travoprost $0.004 \%$. Each subject was issued a TDA to record the time and date of each drop instilled. Informed consents were signed and the subjects were aware that their medication use was being monitored. Patients returned for follow-up 30-60 days after their initial exam.

Results: 89 subjects completed the study: 44 were male, with a mean age of 67 years, and $69.7 \%$ were Caucasian. Overall, patient adherence was $74.8 \%$ (range $22 \%-100 \%$ ) improving to $85.4 \%$ on the day prior to follow-up. The mean number of missed doses per month was $6.24 \pm 5.9$. Only $7.9 \%$ of the study population never missed a dose and $23.6 \% \pm 4.3 \%$ missed more than ten drops per month. No marked association was observed between the severity of glaucoma, race, or the number of systemic medications and adherence. A marked improvement in adherence was noted in patients using travoprost $0.004 \%$ as monocular therapy rather than binocular therapy, $84.0 \% \pm 17.1 \%$ vs $67.4 \% \pm 23.5 \%(P<0.005)$.

Conclusion: Patient adherence to glaucoma medical therapy is a major barrier in the management and treatment of glaucoma patients given the chronic nature and asymptomatic course of the disease. Until recently, an objective tool has not been available to the clinician to identify individual patients' rate of adherence. The TDA is an accurate, adjunctive tool available for assessing patient adherence on an individual level.

Keywords: Glaucoma, adherence, therapy, travatan, medication, travoprost, monitoring

\section{Introduction}

Glaucoma is one of the leading causes of blindness worldwide. ${ }^{1,2}$ Several multi-centered studies have found that successful and consistent IOP lowering may result in both a decreased risk of developing progressive optic nerve damage and the prevention of progression of visual field deterioration..$^{3-7}$ Over a decade has passed since the introduction of prostaglandin analogs, which have greatly simplified glaucoma medical therapy. These medications are currently used as first-line treatment because of their once-daily dosing and ability to effectively control intraocular pressure (IOP) in a relatively safe manner.

DiMatteo ranked eye disorders among the top five diseases, along with sleep disorders, diabetes, and pulmonary diseases in terms of poor adherence to medical 
therapy. ${ }^{8}$ Over 20 years ago, Kass and coworkers found in two distinct studies, in which patients did not know they were being monitored, that patients were poorly adherent with relatively short-term glaucoma therapy with either four times daily pilocarpine $\mathrm{HCl}$ or twice daily timolol maleate. ${ }^{9-11}$ Since that time, various methods have been used to measure patient adherence to glaucoma medications including an electronic monitor sensitive to when a bottle was opened and inverted, ${ }^{9-11}$ patient questionnaires and interviews, ${ }^{12-14}$ and analysis of prescription refill data. ${ }^{14}$ Research has proven that patients overestimate their rate of adherence and physicians are unable to accurately determine who is noncompliant. ${ }^{15}$ Although there are limitations, electronic monitoring devices have been found to be the most objective method for monitoring patient adherence to medications. ${ }^{16,17}$

We know of many risk factors for glaucoma progression, including but not limited to age, race, and IOP. Another major risk factor for glaucoma progression may be adherence. Non-adherence to medical treatment can be defined in many ways: failure to use the medication, failure to use the proper dose of medication (ie, twice daily [BID] medication dosed as once daily [QD]), failure to use the medication at the proper time of day (adequate amount of time between doses), overuse of medications, and failure to persist with dosing regimen. ${ }^{18}$ Past research has determined that two main reasons for nonadherence are due to patient forgetfulness and difficulty with instilling the medication properly. ${ }^{13,19}$

Currently, the Travatan Dosing Aid (TDA) ${ }^{\mathrm{TM}}$ is the only FDA-approved ophthalmic compliance monitor. Several studies $^{20-26}$ to date have evaluated and verified the accuracy and the ease of use of the TDA. Among these studies, however, adherence has not been objectively assessed in relationship to patients' age, stage of disease, and the number of ocular or systemic medications.

We evaluated the adherence rates of 100 consecutive subjects with various forms of glaucoma to determine the effect certain factors including demographic characteristics, other comorbidities, type and severity of glaucoma, and dosing of topical medications had on individual rates of adherence with travoprost $0.004 \%$.

\section{Methods}

This was an open-label, nonrandomized study of 100 consecutive patients enrolled from a private, subspecialty glaucoma practice. The study was conducted in adherence with the Declaration of Helsinki and was approved by the Institutional Review Board (IRB). The investigation was performed prior to the necessity of submitting studies to the National Clinical Trial Registry. All participating patients gave both written and oral consent. We informed all participants that we would be monitoring their adherence to medication through the use of the TDA. Inclusion criteria were: use of travoprost $0.004 \%$ either as monotherapy or adjunctive therapy, 18 years of age or older, ability to return for follow-up visits, self-instillation of eye drops, and previous diagnosis and treatment for any form of glaucoma. Patients with prior laser treatment and intraocular surgeries including glaucoma filtering surgery or cataract surgery were included in the study. Exclusion criteria included any patient with a known hypersensitivity to travoprost $0.004 \%$.

In 2006, the FDA approved the Travatan ${ }^{\mathrm{TM}}$ Dosing Aid (TDA) as the first commercially available monitoring device. This dosing aid provides the user with both visual and audio reminders. The TDA also provides the eye care professional with information about the patient's dosing schedule including the time, date, and number of drops dispensed. Each event is recorded once the handle of the device is depressed. ${ }^{19-22}$

The study consisted of two visits, 30-60 days apart. At the initial visit, subjects completed a questionnaire on demographics and eyedrop use, were issued a dosing aid, and a trained technician gave instructions on its use in conjunction with prescribed travoprost $0.004 \%$. Each subject was also given a $2.5-\mathrm{mL}$ sample bottle of travoprost $0.004 \%$. At the second examination, the TDA was returned to the examiner; data was retrieved using proprietary software, and then analyzed. We evaluated age, race, marital status, education background, number of systemic medications, ophthalmic and systemic comorbidities, number of topical ocular hypotensive medications, daily frequency of topical medication use, and severity of glaucoma as measured by mean deviation on Humphrey visual field testing, and correlated these factors with individual patient dosing with the dosing aid.

We defined adherence as a dose instilled within a 24-hour time window. We did not evaluate overdosing. For statistical analysis, we used a non-paired Student's $t$-test to determine differences in continuous variables (rates of adherence) between groups. We defined statistical significance as $P<0.05$.

\section{Results}

Of the 100 consecutive patients enrolled in the study, 89 completed the study. Eleven patients were lost to followup; their baseline characteristics did not significantly differ from those who were included. Baseline characteristics of the study group are listed in Table 1 . The mean age of the study group was $67 \pm 16.0$ years, 47 (52.8\%) were male, 
and the majority were Caucasian (69.7\%). Humphrey visual field (HVF) mean deviation was $-5.1 \pm 7.3 \mathrm{~dB}$. The study population had several systemic comorbidities and was using an average of $4.3 \pm 6.6$ systemic prescription medications in addition to their prescribed glaucoma treatment (Table 1). We did not record the number of nonprescription medications. Forty-one (46.1\%) of the study patients were using adjunct therapy in addition to the study medication with 74 (82.9\%) using the adjunctive treatments twice or three times daily (Table 2).

The overall rate of adherence was $74.8 \% \pm 22.4 \%$ (Table 3). Adherence improved to $85.4 \% \pm 0.4 \%$ the day prior to the scheduled follow-up exam. The mean number of missed doses per month was $6.24 \pm 5.9$ and the average number of days missed throughout the study period was $9.9 \pm 11.9$ days. Only $7.9 \%$ of the study population never missed any drops per month, while $23.6 \% \pm 4.3 \%$ of the population missed more than ten drops per month (Table 3).

The rates of adherence were compared between groups as continuous variables using non-paired Student's $t$-tests. Gender was not a significant factor $(P=0.33)$ influencing patient adherence. There was a significant difference between Caucasians and those of African descent $(P=0.003)$ (Table 4). Patients with a postgraduate degree demonstrated better adherence $(83.6 \% \pm 11.7 \%)$ when compared to patients who did not complete high school $(66.1 \% \pm 29.5 \%)$ $(P=0.059)$ (Table 4). Divorced and widowed patients apparently had lower rates of adherence than single or married patients $(P=0.003)$ (Table 4$)$.

We observed no association between adherence and severity of glaucoma (Table 5). Patients diagnosed with primary open-angle glaucoma demonstrated poorer adherence than those diagnosed with other forms of glaucoma $(P=0.05)$ (Table 5). A marked increase in adherence was noted for patients using travoprost $0.004 \%$ as monocular therapy rather than binocular therapy, $84.0 \% \pm 17.1 \%$ vs $67.4 \% \pm 23.5 \%(P<0.005)$ (Table 6). Adherence also appeared to be improved in patients using once-daily adjunct therapies vs those using twice-daily adjunct therapies, $81.5 \% \pm 23.1 \%$ vs $74.2 \% \pm 22.8 \%$, though this difference did not reach statistical significance $(P=0.4)$ (Table 6). Both of these comparisons are made cautiously in the context of a sample size of 89 patients; however these findings are supported by the principle that with a simpler regimen, adherence is improved, which has been reported previously. ${ }^{12,13,26}$ There was no relationship between adherence and the number of systemic medications being used by the study patients $(P=0.56)$ (Table 6$)$.
Table I Pre-study characteristics of patients

\begin{tabular}{|c|c|c|}
\hline & $\mathbf{n}$ & $\%$ \\
\hline \multicolumn{3}{|l|}{ Age } \\
\hline $\mathrm{N}$ & 89 & \\
\hline Mean \pm SD & $67.0 \pm 16.0$ & \\
\hline Minimum, maximum & 20,91 & \\
\hline \multicolumn{3}{|l|}{ Gender } \\
\hline Male & 47 & 52.8 \\
\hline Female & 42 & 47.2 \\
\hline \multicolumn{3}{|l|}{ Race } \\
\hline Caucasian & 62 & 69.7 \\
\hline African American & 22 & 24.7 \\
\hline Asian & 1 & I.I \\
\hline Other & 4 & 4.5 \\
\hline \multicolumn{3}{|l|}{ Highest education level completed } \\
\hline High school & 28 & 31.5 \\
\hline College & 9 & 10.1 \\
\hline Postgraduate & 9 & 10.1 \\
\hline Other & 4 & 4.5 \\
\hline Unknown & 39 & 43.8 \\
\hline \multicolumn{3}{|l|}{ Marital status } \\
\hline Single & 10 & 11.2 \\
\hline Married & 57 & 64.0 \\
\hline Divorced & 7 & 16.9 \\
\hline Widowed & 15 & 7.9 \\
\hline \multicolumn{3}{|l|}{ Comorbidities } \\
\hline Diabetes & 19 & 21.4 \\
\hline Hypertension & 54 & 61.1 \\
\hline Cardiovascular & 14 & 15.7 \\
\hline Stroke & 2 & 2.3 \\
\hline Hormone replacement therapy & 3 & 3.4 \\
\hline Hypercholesterolemia & 23 & 26.4 \\
\hline Migraine & 5 & 6.0 \\
\hline Other & 58 & 65.2 \\
\hline \multicolumn{3}{|l|}{ Diagnosis } \\
\hline Open-angle glaucoma & 59 & 66.3 \\
\hline Normal tension glaucoma & 7 & 7.8 \\
\hline Angle closure glaucoma & 3 & 3.4 \\
\hline Chronic mixed glaucoma & 3 & 3.4 \\
\hline Pigment dispersion glaucoma & 5 & 5.6 \\
\hline Pseudoexfoliation glaucoma & I & I.I \\
\hline Uveitic glaucoma & I & I.I \\
\hline Traumatic glaucoma & 3 & 3.4 \\
\hline Other & 7 & 7.9 \\
\hline No. of systemic medications, mean $\pm S D$ & $4.3 \pm 6.6$ & \\
\hline
\end{tabular}

Abbreviation: SD, standard deviation.

\section{Discussion}

This study, unlike previous glaucoma adherence studies using the TDA, objectively assessed patient adherence looking for factors influencing rates of adherence. We examined the relationship between demographic characteristics, classification and severity of glaucoma, systemic comorbidities, complexity of topical medication dosing, and adherence to once daily travoprost $0.004 \%$. Past studies have found that patients are unable to accurately assess their own compliance and physicians are unable to correctly identify patients at risk 
Table 2 Medication type and dosing of the study population

\begin{tabular}{lll}
\hline & $\mathbf{n}$ & $\%$ \\
\hline Travoprost 0.004\% & & \\
$\quad$ Monocular treatment & 40 & 44.9 \\
$\quad$ Binocular treatment & 49 & 55.1 \\
Adjunctive hypotensive treatment & & \\
No adjunctive treatment & 48 & 53.9 \\
Adjunctive treatment & 41 & 46.1 \\
QD dosing & 7 & 17.1 \\
BID dosing & 34 & 82.9 \\
\hline
\end{tabular}

Abbreviations: QD, once daily; BID, twice daily.

of defaulting from treatment. ${ }^{26}$ Patel and Spaeth determined that the most common reasons for noncompliance were forgetfulness, being away from home, and inconvenient timing and high frequency of dosing. ${ }^{12}$ Osterberg and Blaschke reported that one of the most effective and accurate methods for determining patient adherence is through the implementation of electronic recording devices. ${ }^{17}$ These devices allow the physician to identify patients who are in need of intervention to improve compliance. Osterberg and Blaschke also stated that simple dosing (once a day) aids in patient compliance. ${ }^{17}$

With the introduction of prostaglandin analogs over a decade ago, we have a relatively effective and safe once daily medication for first-line treatment. The TDA provides the patient with audio and visual reminders to help eliminate forgetfulness, which is a major obstacle of patient adherence. The TDA is a valuable diagnostic tool, giving physicians the ability to determine adherence on an individual level. The dosing aid is easily connected to a computer via a dock and USB connection, and once connected, the individual's information is downloaded. The data is available in both a list view and a calendar view that can be printed out to review with the patients during their exam.

Table 3 Percent of adherence with travoprost $0.004 \%$

\begin{tabular}{ll}
\hline Adherence & Mean \pm SD \\
\hline $\begin{array}{l}\text { Overall rate of adherence } \\
\text { Rate of adherence } 7 \text { days prior to follow-up }\end{array}$ & $74.8 \% \pm 22.4 \%$ \\
7 days prior & $72.0 \% \pm 0.5 \%$ \\
6 days prior & $63.0 \% \pm 0.5 \%$ \\
5 days prior & $70.0 \% \pm 0.5 \%$ \\
4 days prior & $75.3 \% \pm 0.4 \%$ \\
3 days prior & $75.3 \% \pm 0.4 \%$ \\
2 days prior & $75.3 \% \pm 0.4 \%$ \\
I day prior & $85.4 \% \pm 0.4 \%$ \\
\hline
\end{tabular}

Notes: Adherence was defined as the number of doses taken in a 24-hour period of time. The increasing adherence on days approaching a subject's follow-up visit demonstrates "white coat phenomenon".

Abbreviation: SD, standard deviation.
Table 4 Rate of adherence (\%) in relation to demographic characteristics of the study sample

\begin{tabular}{lll}
\hline & \% Adherence \pm SD & P value \\
\hline Gender $(\mathrm{n}=89)$ & & \\
Male & $76.7 \pm 21.7$ & 0.33 \\
Female & $72.8 \pm 23.2$ & \\
Race $(\mathrm{n}=89)$ & & \\
Caucasian & $79.0 \pm 21.5$ & 0.003 (C vs A-A) \\
African American & $61.5 \pm 22.2$ & \\
Other & $80.4 \pm 9.5$ & \\
Highest level of education completed $(\mathrm{n}=89)$ & \\
High school & $74.7 \pm 21.7$ & \\
College & $76.7 \pm 17.3$ & 0.059 (PG vs did \\
Postgraduate & $83.6 \pm 11.7$ & not complete HS) \\
Did not complete & $66.1 \pm 29.5$ & \\
high school & & \\
Marital Status $(\mathrm{n}=89)$ & & \\
Single & $73.2 \pm 30.2$ & 0.003 (S/M vs D/W) \\
Married & $80.3 \pm 18.5$ & \\
Divorced & $46.3 \pm 17.7$ & \\
Widowed & $68.6 \pm 22.1$ & \\
\hline
\end{tabular}

Abbreviations: SD, standard deviation; C, Caucasian; A-A, African American; HS, high school; PG, post-graduate; S/M, single/married; D/W, divorced/widowed.

Using the TDA, we followed 89 patients for up to 2 months to determine trends in adherence. The overall rate of adherence was approximately $75 \%(74.8 \% \pm 22.4 \%)$. This was similar to the findings from Kass's study in which patients had approximately $76 \%$ adherence. ${ }^{9}$ Also similar to findings by Kass et $\mathrm{al}^{9}$ and Robin et al, ${ }^{27}$ a white-coat phenomenon was observed with patient adherence to travoprost $0.004 \%$ increasing in the 24-hour period preceding the return appointment, to $85.4 \%$.

Unlike the findings by Hollo et al, we found a relationship between certain demographic characteristics and adherence. ${ }^{28}$ There was a marked association found between rate of adherence and race, level of education, and marital status. Caucasians demonstrated better adherence than African Americans (Table 4), although this was not clinically significant. Patients who completed postgraduate studies were more adherent than those who did not complete high school (Table 4). Marital status also seemed to be a factor influencing adherence with those who were married or single demonstrating improved adherence over those who were either divorced or widowed $(P=0.003)$, though we must consider our small sample size (Table 4). No clinical significance was found between gender and rate of adherence, likely due to the small sample size. Simpler ophthalmic dosing schedules demonstrated improved adherence. Patients using travoprost $0.004 \%$ in one eye had better rates of adherence than those using binocular treatment $(84.0 \% \pm 17.1 \%$ vs $67.4 \% \pm 23.5 \%)(P<0.005)$ (Table 5$)$. Adherence also appeared to be improved for patients using 
Table 5 Rate of adherence (\%) based on varying forms of glaucoma and severity of disease

\begin{tabular}{|c|c|c|}
\hline & $\%$ Adherence \pm SD & $P$ value \\
\hline \multicolumn{3}{|l|}{ Form of glaucoma } \\
\hline Primary open-angle glaucoma & $70.3 \pm 24.2$ & \\
\hline Normal tension glaucoma & $83.6 \pm 14.6$ & \\
\hline Angle closure glaucoma & $83.3 \pm 12.8$ & \\
\hline $\begin{array}{l}\text { Chronic mixed mechanism } \\
\text { glaucoma }\end{array}$ & $84.1 \pm 7.1$ & \\
\hline Pigment dispersion glaucoma & $91.5 \pm 10.4$ & \\
\hline Pseudoexfoliation glaucoma & 97.0 & \\
\hline Uveitis & 60.0 & \\
\hline Traumatic & $80.0 \pm 26.9$ & \\
\hline Other & $81.8 \pm 16.3$ & \\
\hline \multicolumn{3}{|l|}{ Severity of glaucoma based on MD } \\
\hline \multicolumn{3}{|l|}{ Mean deviation OD } \\
\hline$\leq-6$ & $74.2 \pm 22.8$ & \\
\hline$-6>M D<-12$ & $83.1 \pm 19.2$ & \\
\hline$\geq-12$ & $70.2 \pm 23.0$ & \\
\hline \multicolumn{3}{|l|}{ Mean deviation OS } \\
\hline$\leq-6$ & $74.1 \pm 21.4$ & \\
\hline$-6>M D<-12$ & $78.5 \pm 23.2$ & \\
\hline$\geq-12$ & $79.8 \pm 21.6$ & \\
\hline
\end{tabular}

Notes: Severity of glaucoma was defined in this study as mild, moderate or severe based on the mean deviation from the Humphrey visual field. Mild disease was considered $M D \leq-6$, moderate disease was for MD $-6>M D>-12$ and severe disease was considered $M D \geq-12$.

Abbreviations: MD, mean deviation; SD, standard deviation; OD, right eye; OS, left eye.

adjunct therapy as once daily vs twice daily, however, there was no statistical significance. Although the numbers are small, we also found a potential association between adherence and the type of glaucoma with better adherence observed in patients with primary open-angle glaucoma. Adherence was

Table 6 Rates of adherence (\%) for patients being treated with travoprost $0.004 \%$ monocularly and binocularly, with adjunct therapies, and using multiple systemic medications

\begin{tabular}{lll}
\hline Category & \% Adherence \pm SD & $P$ value \\
\hline $\begin{array}{l}\text { Travoprost 0.004\% } \\
\text { Monocular treatment }\end{array}$ & $84.0 \pm 17.1$ & \\
$\quad$ Binocular treatment & $67.4 \pm 23.5$ & $P<0.005$ \\
Adjunct therapy & & \\
$\quad$ One addition medication & $74.6 \pm 22.0$ & \\
Two or more additional & $75.1 \pm 23.1$ & \\
medications & & \\
Dosing of adjunct therapy & & \\
$\quad$ QD dosing & $81.5 \pm 23.1$ & \\
$\quad$ BID dosing & $74.2 \pm 22.8$ & \\
Systemic medications & & \\
$\quad \leq 4$ systemic medications & $76.5 \pm 20.3$ & $P=0.35$ \\
$\quad>5$ systemic medications & $71.3 \pm 26.3$ & \\
\hline
\end{tabular}

Abbreviations: SD, standard deviation; QD, once daily dosing; BID, twice daily dosing. not influenced by the severity of disease as defined by mean deviation on Humphrey visual field.

The study is not without limitations. The patients included in the study were all being managed in a glaucoma private practice. Therefore results may not be generalizable due to practice location, type of practice, and use of Travatan vs other medications for glaucoma. The subjects of this study knew they were being monitored, which may have increased patient adherence. The duration of the study was only 2 months, which is a short time to monitor patients being treated for a chronic disease. Although the TDA recorded the time and amount of medication used, there is no way to determine that the drop was properly instilled into the eye, the number of drops administered, or that the medication was in fact used. The TDA does not allow for the monitoring of other topical ocular hypotensive medications. Longer-term studies are needed to better determine adherence rates in glaucoma therapy.

In conclusion, understanding common barriers of nonadherence in glaucoma management is the first step in improving treatment outcomes. Past research combined with new technology such as medication monitoring devices allow patients' adherence to be evaluated on an individual basis, decreasing their risk of future vision loss. The TDA is not available for all ocular hypotensive medications in use, but the information learned from this study and future studies objectively monitoring patient adherence provides clinicians with valuable information about the possible characteristics of high-risk patients. This information may be used to provide education and intervention helping to increase adherence and thus improve treatment outcomes.

\section{Acknowledgment}

The dosing aids were provided without cost by Alcon Laboratories however, no other funding was given for this study.

\section{Disclosure}

The authors report no conflicts of interest in this work.

\section{References}

1. Congdon N, O'Colmain B, Klaver CC, et al. Causes and prevalence of visual impairment among adults in the United States. Arch Ophthalmol. 2004;122(4):477-485.

2. Quigley HA, Broman AT. The number of people with glaucoma worldwide in 2010 and 2020. Br J Ophthalmol. 2006;90(3):262-267.

3. Musch DC, Lichter PR, Guire KE, Standardi CL. The collaborative initial glaucoma treatment study: study, design, methods and baseline characteristics of enrolled patients. Ophthalmology. 1999;106(4):653-662.

4. The AGIS Investigators. The Advanced Glaucoma Intervention Study (AGIS):7. The relationship between control of intraocular pressure and visual field deterioration. Am J Ophthalmol. 2000;130(4):429-440. 
5. HeijlA, Leske MC, Bengtsson B, et al. Reduction of Intraocular Pressure and Glaucoma Progression: Results from the Early Manifest Glaucoma Trial. Arch Ophthalmol. 2002;120(10):1268-1279.

6. Comparison of glaucomatous progression between untreated patients with normal tension glaucoma and patients with therapeutically reduced intraocular pressures. Collaborative Normal-Tension Glaucoma Study Group. Am J Ophthalmol. 1998;126(4):487-497.

7. Kass MA, Heuer DK, Higginbotham EJ, et al. The Ocular Hypertensive Treatment Study: a randomized trial determines that topical ocular hypotensive medication delays or prevents the onset of primary openangle glaucoma. Arch Ophthalmol. 2002;120:701-713.

8. DiMatteo MR. Variations in patients' adherence to medical recommendations: a quantitative review of 50 years of research. Med Care. 2004;42(3):200-209.

9. Kass MA, Meltzer DW, Gordon M, et al. Compliance with topical pilocarpine treatment. Am J Ophthalmol. 1986;101(5):515-523.

10. Kass MA, Gordon M, Meltzer DW. Can ophthalmologists correctly identify patients defaulting from pilocarpine therapy? Am J Ophthalmol. 1986;101:524-530.

11. Kass MA, Gordon M, Morley RE, Meltzer DW, Goldberg JJ. Compliance with topical timolol treatment. Am J Ophthalmol. 1987;103(2): 188-193.

12. Patel SC, Spaeth GL. Compliance in patients prescribed eye drops for glaucoma. Ophthalmic Surgery. 1995;26(3):233-236.

13. Tsai JC, McClure CA, Ramos SE, Schlundt DG, Pichert JW. Compliance barriers in glaucoma: a systematic classification. J Glaucoma. 2003; 12(5):393-398.

14. Winfield AJ, Jessiman D, Williams A, Esakowitz L. A study of the causes of non-compliance by patients prescribed eyedrops. $\mathrm{Br} J$ Ophthalmol. 1990;74(8):477-480.

15. Vrjens B, Tousset E, Rode R, Bertz R, Mayer S, Urquhart J. Successful projection of the time course of drug concentration in plasma during a 1 -year period from electronically complied dosing-time Data used as input to individually parameterized pharmacokinetic models. J Clin Pharmacol. 2005;45(4):461-467.

16. Farmer KC. Methods for measuring and monitoring medication regimen adherence in clinical trials and clinical practice. Clin Ther. 1999;21(6):1074-1090.
17. Osterberg L, Blaschke T. Adherence to medication. $N$ Engl J Med. 2005;353(3):487-497.

18. Grandstrom P. Glaucoma patients not compliant with their drug therapy: clinical and behavioral aspects. Br J Ophthalmol. 1982;66(7): 464-470.

19. Sleath B, Robin AL, Covert D, Byrd JE, Tudor G, Svarstad B. Patientreported behavior and problems in using glaucoma medications. Ophthalmology. 2006;113(3):431-436.

20. Friedman D, Jampel H, Congdon N, Miller R, Quigley HA. The Travatan dosing aid accurately records when drops are taken. Am J Ophthalmol. 2007;143(4):699-701.

21. Flowers B, Wand M, Piltz-Seymour J, et al. Patients' and physicians' perception of the travatan dosing aid: an open-label, multicenter study of adherence with prostaglandin analogue therapy for open-angle glaucoma or ocular hypertension. Clin Ther. 2006;28(11):1803-1811.

22. Boden C, Sit A, Weinreb RN. Accuracy of an electronic monitoring and reminder device for use with travoprost eye drops. J Glaucoma. 2006;15(1):30-34.

23. Okeke CO, Quigley HA, et al. Interventions improve poor adherence with once daily glaucoma medications in electronically monitored patients. Ophthalmology. 2009;116(12):2286-2293.

24. Ho LY, Camejo L, Kahook MY, Noecker R. Effect of audible and visual reminders on adherence in glaucoma patients using a commercially available dosing aid. Clin Ophthalmol. 2008;2(4):769-772.

25. Friedman DS, Okeke CO, Jampel HD, et al. Risk factors for poor adherence to eyedrops in electronically monitored patients with glaucoma. Ophthalmology. 2009;116(6):1097-1105.

26. Okeke CO, Quigley HA, Jampel HD, et al. Adherence with topical glaucoma medication monitored electronically the Travatan Dosing Aid study. Ophthalmology. 2009;116(2):191-199.

27. Robin AL, Novack GD, Covert DW, Crockett RS, Marcic TS. Adherence in glaucoma: objective measurements of once-daily and adjunctive medication use. Am J Ophthalmol. 2007;144(4):533-540.

28. Hollo G, Kothy P, Geczy A, Vargha P. Personality traits, depression, and objectively measured adherence to once-daily prostaglandin analog medication in glaucoma. J Glaucoma. 2009;18(4):288-292.
Clinical Optometry

\section{Publish your work in this journal}

Clinical Optometry is an international, peer-reviewed, open access journal publishing original research, basic science, clinical and epidemiological studies, reviews and evaluations on clinical optometry. All aspects of patient care are addressed within the journal as well as the practice of optometry including economic and business analyses. Basic and clinical Submit your manuscript here: http://www.dovepress.com/clinical-optometry-journal

\section{Dovepress}

research papers are published that cover all aspects of optics, refraction and its application to the theory and practice of optometry. The manuscript management system is completely online and includes a very quick and fair peer-review system, which is all easy to use. Visit http://www.dovepress. com/testimonials.php to read real quotes from published authors. 